\title{
Studi Life Cycle Assessment Produksi Gula Tebu: Studi Kasus di Jawa Timur
}

\author{
Marudut Sirait \\ Teknik Industri, Universitas Brawijaya \\ marudut@ub.ac.id
}

DOI: https://doi.org/10.21107/rekayasa.v13i2.5915

\begin{abstract}
The purpose of this paper is to identify potential environmental impacts during the process of sugarcane production in East Java, Indonesia. This study utilized Life Cycle Assessment (LCA) approach to evaluate the environmental impact during the manufacturing of sugar cane. LCA analysis focuses on processing sugarcane, which consists of the preparation process, the milling process, centrifugal separation, the clarification process, the evaporation process, and the crystalization process. The Life Cycle Impact Assessment (LCIA) was expressed by the EDIB 2003 method. The result showed that the most significant environmental impacts on environmental degradation were global warming, acidification, eutrophication, human toxicity of water, and ozone depletion. Furthermore, the production process with the greatest contribution to environmental impact were the miling process, followed by centrifugal seperation process, clarification process, crystallization process, evaporation process, and preperation process for all categories of environmental impacts..
\end{abstract}

Life Cycle Assessment Study of Sugarcane: The case of East Java

Keywords: Environmental Impact, Energy, Sugarcane, Global Warming, Life Cycle Assessment

\section{ABSTRAK}

Tujuan dari makalah ini adalah untuk mengidentifikasi potensi dampak lingkungan selama proses produksi gula tebu di Jawa Timur Indonesia. Studi ini menggunakan pendekatan Life Cycle Assesment (LCA) untuk mengevaluasi dampak lingkungan selama proses produksi gula dari tebu. Analisis LCA fokus pada pengolahan tebu menjadi gula, yang terdiri dari proses persiapan, proses miling, centrifugal separation, proses clarification, proses evaporation, dan proses crystalization. Hasil Life Cycle Impact Assessment (LCIA) diekpresikan dengan metode EDIB 2003, menunjukkan bahwa dampak lingkungan yang paling signifikan terhadap penurunan kualitas lingkungan adalah global warming, acidification, eutrofikasi, human toxicity air, dan ozone depletion. Selanjutnya, proses produksi gula yang paling besar kontribusnya pada dampak lingkungan adalah proses penggilingan/miling, diikuti oleh proses centrifugal seperation,proses clarification, proses crystallization,proses evaporation, dan proses preperation untuk semua kategori dampak lingkungan.

Kata Kunci: Dampak Lingkungan, Energi, Gula Tebu, Global Warming, Life Cycle Assessment

\section{PENDAHULUAN}

Gula adalah produk yang sangat penting untuk konsumsi manusia dalam kehidupan sehari-hari. Produk hasil gula bukan hanya makanan tetapi juga untuk produk lain. Produk utama tebu adalah molase dan biogase (Renó et al., 2011). Molase digunakan sebagai pengganti gula dan biogase menggunakan bioelektrik (Murugan \& Ranjit Singh, 2012). Oleh karena itu, tebu adalah salah satu agroindustri terbesar yang menghasilkan industri gula dan etanol .Akibatnya, jumlah produksi gula meningkat sangat besar di seluruh dunia saat ini untuk memenuhi kebutuhan manusia dan industri. Beberapa peneliti mengatakan bahwa produksi gula dunia adalah sekitar 145 juta ton setiap tahun (Goldemberg et al., 2008). Dimana negara Brasil, India dan China adalah tiga negara

\section{Article History:}

Received: August, 30 th 2019; Accepted: May, $10^{\text {th }} 2020$

REKAYASA ISSN: 2502-5325 has been Accredited by Ristekdikti (Arjuna) Decree: No. 23/E/KPT/2019 August $8^{\text {th }}$, 2019 effective until 2023 terbesar penghasil tebu dan gula di dunia (Cardona et al., 2010). Di Indonesia sendiri, penggunaan gula adalah sekitar 4,2-4,7 juta ton per tahun (Kementerian Perindustrian Republik Indonesia, 2018). Oleh karena itu, produksi tebu memiliki dampak yang cukup signifikan pada tiga aspek, yaitu aspek ekonomi, aspek lingkungan, dan aspek sosial. Dalam dampak sosial, industri gula dapat menghasilkan pendapatan bagi 900 ribu petani tebu di Indonesia [Direktorat Jenderal Industri Agro dan Kimia,2009). Di sisi lain, dari aspek lingkungan, industri gula menghasilkan banyak kerugian bagi lingkungan. Produksi tebu telah meningkatkan degradasi kulitas lingkungan (Chauhan et al., 2011)(Renouf et al., 2010), Sebagai contoh, selama penanaman dan pengolahan tebu, produksi tebu mengakibatkan degradasi kualitas lingkungan dengan

\section{Cite this as:}

Sirait, M. (2020). Studi Life Cycle Assessment Produksi Gula Tebu: Studi Kasus di Jawa Timur. Rekayasa, 13(2), 197-204. https://doi.org/10.21107/rekayasa.v13i2.5915 
kehilangan habitat alami karena pengunaan lahan, pembuangan dan limpasan limbah cair. Juga polusi udara, penggunaan bahan kimia, penggunaan air dalam jumlah besar, dan pengunaan energi selama proses produksi tebu menjadi gula juga membawa dampak yang cukup significant pada kerusakan lingkungan. Oleh karena itu, untuk mengetahui dan dan mengevaluasi sejauh mana dampak lingkungan yang dihasilkan dari proses pembuatan gula dari tebu, sehingga perlu dilakukan kajian secara ilmiah dan menyeluruh. Saat ini, salah satu metode yang paling banyak digunakan untuk menilai dampak lingkungan adalah dengan pendekatan life cycle assessment. (LCA). Karena LCA dapat menilai secara menyeluruh, sederhana dan sudah diakui secara international serta digunakan oleh para ahli lingkungan di seluruh dunia. Oleh karena itu penting melakukan kajian produk gula tebu dengan pendekatan LCA untuk mengetahui dampak lingkungan yang ditimbulkanya dan kemudian melakukan langkah-langkah strategis untuk mengurangi dampak lingkungan tersebut, seperti dengan pendekatan produksi bersih (cleaner production) (Sirait, 2018)

Saat ini, LCA telah diterapkan secara luas pada produk dan proses industri, tetapi penerapannya pada sektor pertanian masih sangat baru. Namun implemetasi LCA sudah mulai digunakan untuk menilai kelestarian lingkungan dari sistem produksi pertanian. Untuk tebu dan produkproduknya, hanya ada beberapa studi LCA yang diterbitkan di berbagai negara seperti analisa dampak lingkungan paroduk gula tebu dari Brasil (Luo et al., 2009)(Hofsetz \& Silva, 2012) dan Thailand (Silalertruksa et al., 2017). Tujuan utama dari kajian ini adalah penilaian penggunaan energi siklus hidup dan emisi gas rumah kaca (GRK) yang terkait dengan gula tebu dan etanol, dengan mempertimbangkan kelebihan ampas tebu dan listrik sebagai coproducts. Studi ini melakukan keseimbangan keseluruhan untuk Pusat Brasil - Wilayah Selatan, mengadopsi metode yang berbeda untuk mengevaluasi produksi gula dan etanol secara terpisah. Model GREET 1.8c.0 digunakan untuk perhitungan 'wellto-wheels' tetapi diadaptasi ke set komprehensif parameter Brasil yang paling mewakili Wilayah Center-Selatan. Penggunaan energi fosil dan emisi GRK terkait produksi gula dievaluasi masing-masing $721 \mathrm{~kJ} / \mathrm{kg}$ dan $234 \mathrm{~g} \mathrm{CO}$ eq / $\mathrm{kg}$. Untuk siklus hidup etanol, nilai-nilai ini adalah $80 \mathrm{~kJ} / \mathrm{MJ}$ dan 21,3 g CO2eq / MJ. Penelitian lain yang mengimplementasikn LCA untuk menilai dampak lingkungan dari poduk gula tebu di Mauritus. Industri gula di Mauritius, 1 ton gula dapat diproduksi dengan menggunakan sumber daya 0,12 lahan, $553 \mathrm{~m}^{3}$ air, bahan bakar fosil 1995 MJ, total konsumsi energi 14,235 MJ (bahan bakar fosil dan baggase) dan menghasilakan dampak lingkungan pada udara adalah $1.7 \mathrm{~kg}$ TSP, $1.21 \mathrm{~kg} \mathrm{SO} 2,1.26 \mathrm{~kg} \mathrm{NOx}, 1.26 \mathrm{~kg} \mathrm{CO}, 0.065$ kg VOC, 0.002 kg CH4, 0.26 kg N2O, 160 kg CO2 (Ramjeawon, 2008) . Implementasi LCA pada gula tebu di Australia juga menghasilkan dampak yang sangat significant pada penurunan kulitas (Renouf et al., 2010)(Anne Renouf et al., 2011). Walaupun penelitian life cycle assessment pada gula tebu dari berbagai negara sudah ada, tetapi penelitian ini berbeda dengan dengan peneltian sebelumnya, karena daerah dan metode yang berbeda. Perbedaan wilayah/ negara akan mempengaruhi hasil dari LCA, Karena teknologi, kultur dan iklim pada suatu daerah pasti berbeda dan hasil LCA juga akan berbeda (Hauschild et al., 2017).

Oleh karena itu, tujuan utama dari makalah ini adalah untuk mengidentifikasi potensi dampak lingkungan khusus pada pengunaan energi selama produksi gula dari tebu. Penelitian ini menggunakan penilaian siklus hidup untuk mengidentifikasi dampak lingkungan selama siklus hidup produksi tebu di Jawa Timur, Indonesia dengan kasus produksi tebu pada PT Kebon Agung, Malang. Dengan mengetahui potensi dampak lingkungan selama proses produksi gula tebu, sehingga nantinya perlu dilakukan perbaikan pada proses yang menghasilkan dampak lingkungan yang paling besar.

\section{METODE PENELITIAN}

Penelitian ini menggunakan pendekatan Life Cycle Assessment (LCA) untuk mengidentifikasi potensi dampak lingkungan selama proses produksi gula tebu. Penelitian dan pengambilan data diambil pada PG Kebon Agung, Malang, Jawa Timur. LCA menghitung input (mis. Tebu, energi,), Pemrosesan (mis. proses milling, pemisahan sentrifugal) dan output (mis. CO2) 
dan menilai potensi dampak lingkungan dari LCA dengan mengikuti langkah-langkah standar sesui dengan petunjuk ISO 14040 (ISO, 2006)(Curran, 2018). Ada empat langkah dalam melaksakan metode LCA, yaitu penentuan tujuan dan ruang lingkup, inventaris siklus hidup, penilaian dampak siklus hidup, dan interpretasi. Semua langkah yang dibahas di bawah ini seperti yang dijelaskan pada Gambar 1.

\section{Penentuan Goal dan Scope}

Langkah pertama dalam melakukan LCA adalah penentuan tujuan dan ruang lingkup dari study LCA yang akan dilakukan. Oleh karena itu tujuan dan ruang lingkup penelitian harus didefinisikan dengan sangat baik untuk memastikan detail penelitian. Selain itu, tujuan harus kompatibel dan cukup untuk memenuhi tujuan yang akan dicapai. Selanjutnya ruang lingkup, termasuk batasan sistem dan tingkat kedetailan LCA mencakup beberapa item, seperti prosedur alokasi, batas sistem, dan unit fungsional. Pada penelitian ini, tujuan dari studi LCA ini adalah untuk mengidentifikasi dampak lingkungan yang potensial untuk menghasilkan 255 ton gula dari tebu. Ruang lingkupnya adalah fokus pada dampak pengunaan energi dan batas-batas penelitian ini adalah untuk melakukan LCA selama produksi tebu, yang terdiri dari proses preparation, , proses miling, proses clarification, proses crystallization, proses centrifugal separation dan proses evaporation.

\section{Inventory Analysis}

Pada tahap life cycle inventory (fase LCI) adalah fase kedua dari LCA. Tahap ini adalah tahap yang paling krusial keberhasilan pelaksanaan LCA. Inventory yang baik akan menghasilkan hasil LCA yang baik. Karena pada tahap ini, yang dilakukan adalah inventarisasi data input/output yang berkaitan dengan sistem yang sedang dipelajari dan juga prosedur perhitungan untuk menghitung input dan keluaran yang relevan dari sistem produk. Hal ini melibatkan pengumpulan data yang diperlukan untuk memenuhi tujuan studi yang ditentukan.

Data untuk setiap unit proses dalam sistem dapat diklasifikasikan berdasarkan kategori, di antaranya adalah input energi, input bahan baku, input tambahan; produk, co-produk dan limbah; emisi ke udara, pembuangan ke air dan tanah; serta aspek lingkungan lainnya. Setelah pengumpulan data, dilakukan prosedur perhitungan yang di dalamnya termasuk validasi data yang dikumpulkan, hubungan data dengan unit proses, dan hubungan data dengan arus referensi dari unit fungsional. Semuanya diperlukan untuk menghasilkan inventaris dari sistem yang ditetapkan untuk setiap unit proses dan untuk unit fungsional dari sistem produk yang akan dimodelkan. Tabel 1 adalah pengunaan energi dan jarak transportasi dari proses produksi gula.

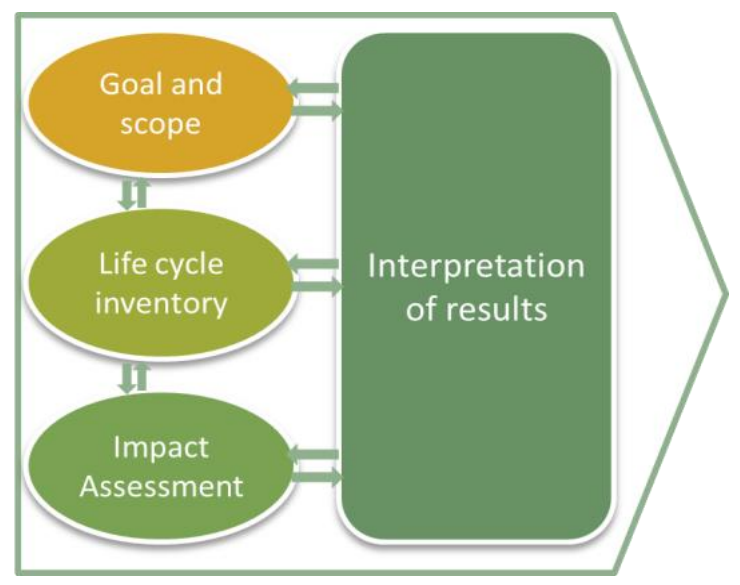

Gambar 1 : Langkah-Langkah pelaksanaan Life Cycle Assessment

Tabel 1. Pengunaan energi dan transportasi pada proses produksi gula tebu

\begin{tabular}{lll}
\hline Input & Proses prosuksi pada gula tebu & Ouput \\
\hline Jarak : $10.319,78 \mathrm{tkm}$ & Transportation & \\
Jarak : $600 \mathrm{tkm}$ & Proses Preperation/persiapan & \\
$1997,39 \mathrm{Kw}$ & Proses Miling & Polusi udara, air dan \\
& tanah \\
$119,06 \mathrm{Kw}$ & Proses Clarification & \\
$28,58 \mathrm{Kw}$ & Proses Crystallization & \\
$101.04 \mathrm{Kw}$ & Proses Centrifugal Separation & \\
$52.56 \mathrm{Kw}$ & Proses Evaporation & \\
\hline
\end{tabular}




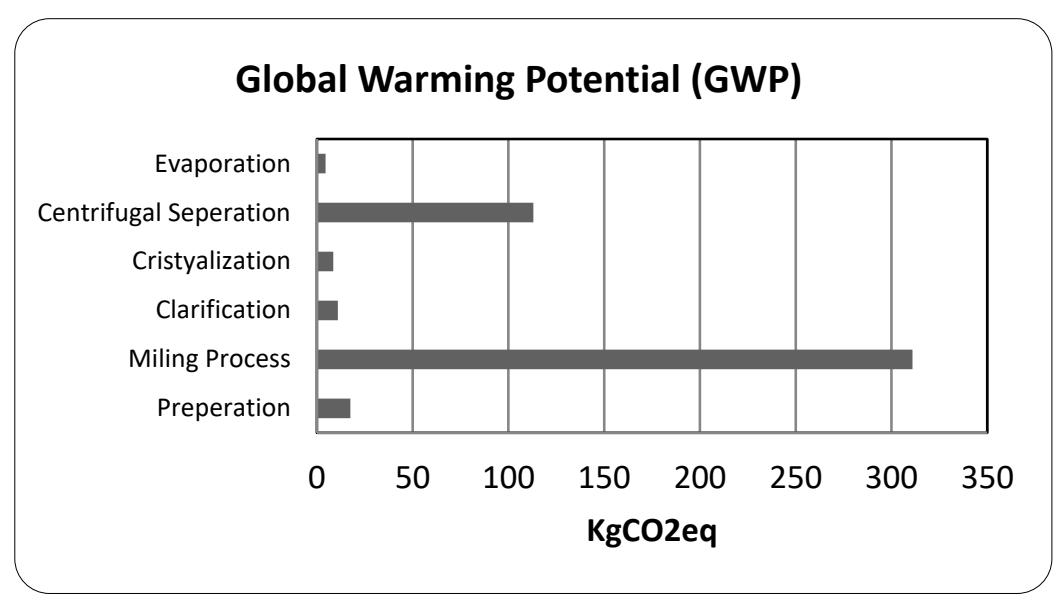

Gambar 2 : Potensi Global Waring pada produksi Gula Tebu

\section{Life Cycle Impact Assessment (LCIA)}

Tahap Life cycle impact assessment (LCIA) adalah mengevaluasi potensi dampak lingkungan dari sumber daya lingkungan yang diidentifikasi selama proses life cycle inventory (LCI.) Penilaian dampak harus mengambarkan dampak ekologis dan dampak kesehatan manusia, juga harus menjelaskan dampak dari pengunaan sumber daya alam. LCl berupaya membangun hubungan antara produk atau proses dan dampak lingkungan yang potensial. Dengan kata lain, penilaian dampak adalah konversi data inventaris menjadi potensi dampak lingkungan kategori dampak, indikasi, dan model karakterisasi. Pada penelitian ini penilaian dampak lingkungan diekpresikan dengan menggunakan metode EDIP 2003, dengan kategori dampak seperti global warming, acidification, ozone depletion, eutrofikasi. Selanjutnya, semua data -data dari proses $\mathrm{LCl}$ dimasukkan ke dalam software simapro 8 untuk menghasilkan kategori dampak lingkungan.

\section{Interpretasi}

Interpretasi siklus hidup adalah fase akhir dari prosedur LCA, di mana hasil $\mathrm{LCl}$ atau LCIA atau keduanya diringkas dan didiskusikan sebagai dasar untuk pengambilan kesimpulan, pemberian rekomendasi dan pengambilan keputusan sesuai dengan definisi tujuan dan ruang lingkup yang telah ditetapkan di tahap awal dari LCA. Interpretasi harus mencerminkan fakta bahwa hasil LCIA didasarkan pada pendekatan relatif, bahwa hal itu mengindikasikan dampak lingkungan yang potensial, dan tidak memprediksi dampak aktual pada titik akhir kategori atau ambang batas.

\section{HASIL DAN PEMBAHASAN}

Studi ini terutama berfokus pada kategori dampak seperti berikut: Global warming Potential (GWP), Acidification potential (AP), Ozone depletion Potential (ODP), Eutrofication Potential (EP), dan Human Toxicity Air (HTP).

\section{Global Warming}

Globar warming adalah meningkatnya suhu ratarata pada atmosfir, laut, dan dartan pada bumi , sehingga bumi lebih panas. Nilai kontribusi global warming pada penurun kulitas lingkungan dinyatakan dengan nilai equivalen, yaitu jumlah gas $\mathrm{CO}_{2}$ yang dilepaskan ke atmosfir ( $\mathrm{KgCO}_{2} \mathrm{eq}$ ). Gambar 2 menunjukkan bahwa selama produksi gula tebu seberat 225 ton memiliki kontribusi terhadap pemanasan global dengan menghasilkan 466KgCO2eq. Dengan proses milling memiliki kontribusi terbesar terhadap potensi pemanasan global dengan memproduksi sekitar $311 \mathrm{KgCO}$ eq (67\%), diikuti oleh proses pemisahan sentrifugal sebesar $113 \mathrm{KgCO} e q$ (24\%), kemudian proses persiapan sebesar $17.5 \mathrm{KgCO}$ eq (4\%), selanjutnya proses klarifikasi memproduksi sebanyak $11 \mathrm{KgCO} 2 \mathrm{eq}(2 \%)$, serta proses kristalisasi melepaskan sebesar 8,59 $\mathrm{KgCO}$ eq (2\%), dan yang terakhir adalah proses penguapan menghasilakn sebesar $4,5 \mathrm{KgCO} e q$ (1\%). Juga dapat diprediksi bahwa kontribusi signifikan dari proses milling dan pemisahan sentrifugal terhadap potensi pemanasan global selama produksi gula tebu disebabkan oleh penggunaan jumlah energi (bahan bakar fosil) 


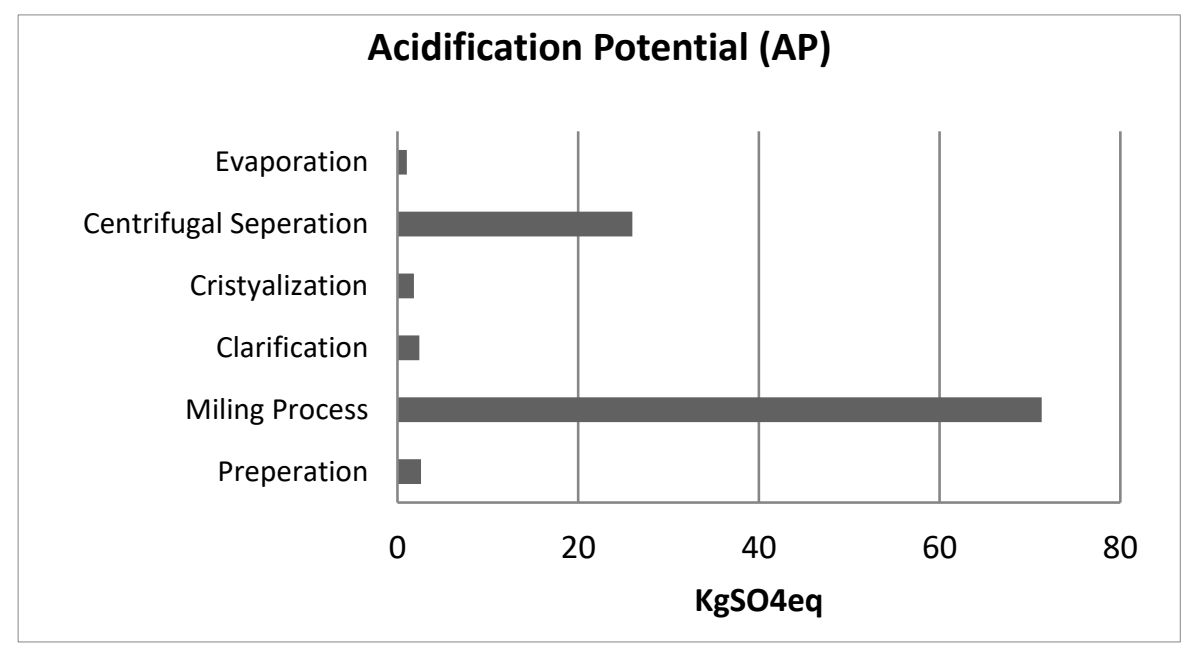

Gambar 3 : Potensi Acidification pada produksi Gula Tebu

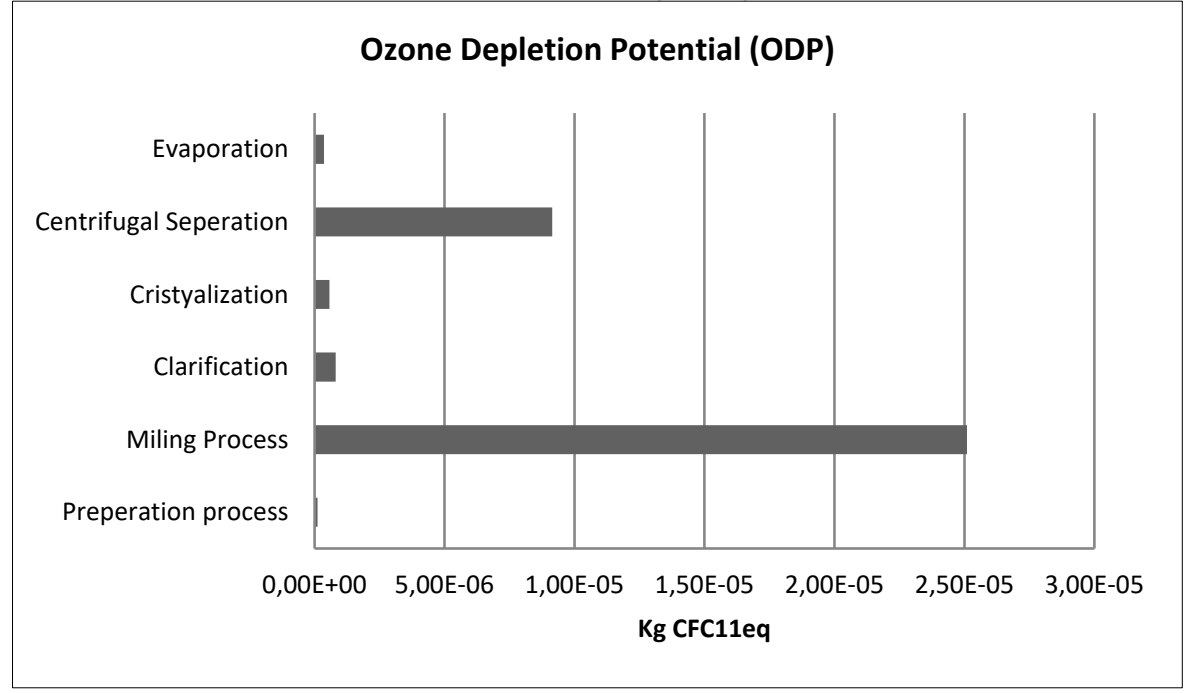

Gambar 4 : Potensi Ozone Depletion pada produksi Gula Tebu

dan listrik terbesar dibandingkan dengan proses lain, seperti proses evaporation.

\section{Acidification.}

Acidification adalah lepasnya gas karbon dioksida $\left(\mathrm{CO}_{2}\right)$, nitrogen $\left(\mathrm{NO}_{x}\right)$ dan $\left.\mathrm{NH}_{2}\right)$ dan sulfur $\left(\mathrm{SO}_{2}\right)$ ke lingkungan. Jumlah potensi dampak lingkungan acidification dinyatkan dalam nilai equivalan $\mathrm{KgSO}_{4}$ eq. Gambar 3 menunjukkan nilai potensi acidification yang dilepaskan pada lingkungan yang dihasilkan dari proses produksi gula tebu sebesar 225 ton. Hasil analisa life cycle impact assessment menunjukkan bahwa selama proses produksi gula potensi Acidification dihasilkan nilai total sekitar 105 KgSO4eq. Dimana proses milling tebu dalam pabrik memiliki kontribusi yang signifikan terhadap potensi terjadinya proses acification, yaitu menghasilkan sebesar $71.3 \mathrm{KgSO} 4 \mathrm{eq}$ (68\%), diikuti oleh proses pemisahan sentrifugal menghasilkan potensi acidification pada lingkungan sebesar $26 \mathrm{KgSO} 4 \mathrm{eq}$ (25\%), proses persiapan menghasilkan potensi sebesar $2.61 \mathrm{KgSO} 4 \mathrm{eq}(2 \%)$, selanjutnya diikuti proses klarifikasi menghasilkan sebanyak $2.43 \mathrm{KgSO} 4 \mathrm{eq}$ (2\%), kemudian proses kristalisasi memproduksi sebesar 1,82 KgSO4eq (25), dan proses penguapan melepaskan sebesar $1,03 \mathrm{KgSO} 4 \mathrm{eq}$ (1\%). Sebagai tambahan, penggunaan energi, bahan baku, dan listrik yang besar selama produksi tebu membuat kontribusi yang signifikan dari proses miling dan proses sepertion centrifugal terhadap potensi terjadinya kategori dampak acidification.

\section{Ozone Depletion}


Ozone depletion adalah penipisan lapisan ozon yang menyebabkan sinar ultraviolet lebih banyak menembus atmodfir bumi. Kerusakan ozone digambarkan dengan jumlah gas CFC yang dilepaskan ke bumi dengan nilai equivalent ( KgCFC11eq). Gambar 4 menunjukkan mengambarkan jumlah gas CFC yang dilepaskan ke atmosfir yang menyebabkan terjadinya ozone depletion selama proses produksi gula tebu sebesar 225 ton. Hasil penilaian dampak lingkungan dari software simapro menghasilkan gas ozone depletion sekitar 0,000361 KgCFC11eq. Hasil penilaian menunjukkan bahwa selama proses produksi gula tebu tidak mempunyai kontribusi secara signifikan terhadap kerusakan lingkungan akibat produksi gas ozone depletion. Hasil menjelaskan bahwa produski gas ozone sangat kecil akibat dari pembakarn bahan bakar fosil selama proses produksi tebu gula. Ini berarti bahwa siklus hidup proses produksi gula melepaskan gas CFC ke lingkungan sangat rendah. Walaupun dampak sangat kecil, tetapi proses millingmasih tetap merupakan kontribusi terbesar terhadap potensi penipisan ozon dengan produksi sebesar 0,00025 KgCFC11eq (70\%), proses pemisahan Sentrifugal memproduksi sebesar 0,0000941KgCFC11eq (25\%), proses klarifikasi menghasilkan sebesar $0,0000081 \mathrm{KgCFC} 11 \mathrm{eq}(2 \%)$, selanjutnya proses kristalisasi meghasilkan sebanyak 0,00000572 KgCFC11eq (2\%), \%), kemudian proses Evaporasi produksi sebesar 0,00000362 KgCFC11eq (1\%), dan yang terakhir adalah proses persiapan menghasilkan sebesar 0,00000117 KgCFC11eq

\section{Eutrofication}

Eutrofikasi adalah pencemaran karena peningkatan nutrisi pada ekosistim air yang dipengaruhi senyawa nitrogen. Jumlah pencemaran dinyatakan dengan jumlah senyawa nitrogen dalam air ( $\mathrm{KgN})$. Hasil penilaian dampak lingkungan pada potensi eutrofikasi sepanjang siklus hidup produksi gula tebu ditunjukkan pada Gambar 5. Dalam memproduksi 255 ton gula tebu, hasil LCA menunjukkan potensi pencemaran lingkungan kategori eutrofikasi sebesar 3,898 KgN. Dimana proses miling merupakan bagian proses produksi yang mempunyai kontribusi terbesar terhadap potensi eutrofikasi dengan menghasilakan sebesar 2,69 $\mathrm{Kg} \mathrm{N}$ (69\%), diikuti dengan proses separation centrifugal sebanyak 0,98 Kg N (25\%), proses clarification menghasilkan sebanyak 0,087 $\mathrm{Kg} \mathrm{N} \mathrm{(2 \% ),} \mathrm{selanjutnya} \mathrm{proses} \mathrm{crystallization}$ memproduksi sebesar 0,0617 $\mathrm{Kg} \mathrm{N}(2 \%)$, dan proses evaporation melepaskan sebesar 0,0388 $\mathrm{Kg} \mathrm{N} \mathrm{(1 \% ),} \mathrm{serta} \mathrm{proses} \mathrm{preperation}$ menghasilkan sebesar 0,0312KgN ( 1\%).

\section{Human Toxicity Air}

Human Toxicity Air adalah polusi lingkungan yang berdampak buruk bagi kesehatan manusia melalui media udara. Jumlah potensi human toxicity air diekspresikan dengan jumlah pollutan dalam $\mathrm{m}^{3}$ di dalam udara. Hasi perhitungan

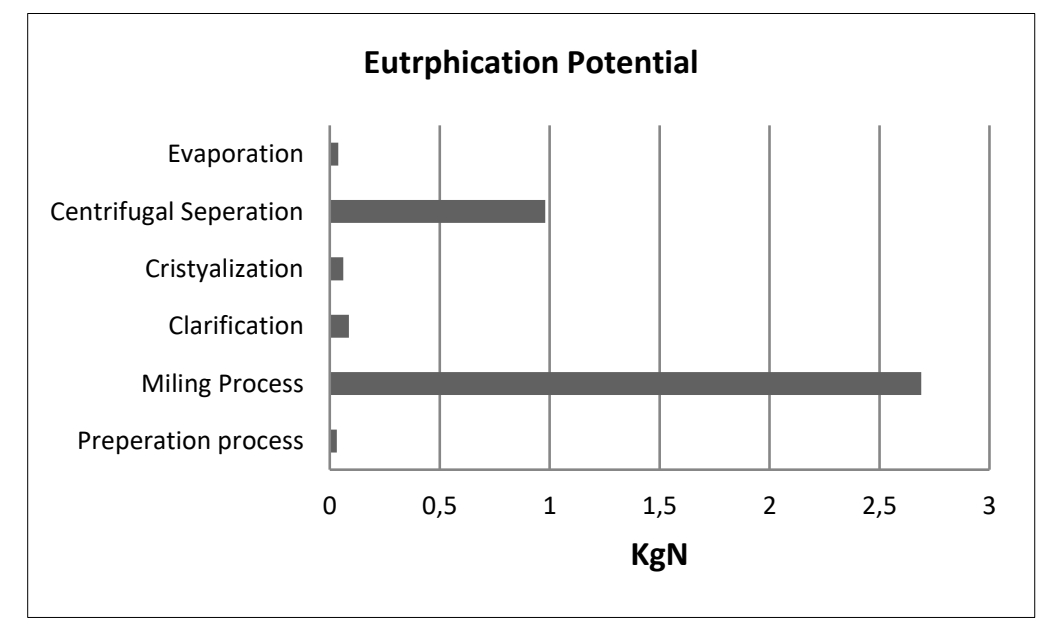

Gambar 5 : Potensi Eutrophication pada produksi Gula Tebu 


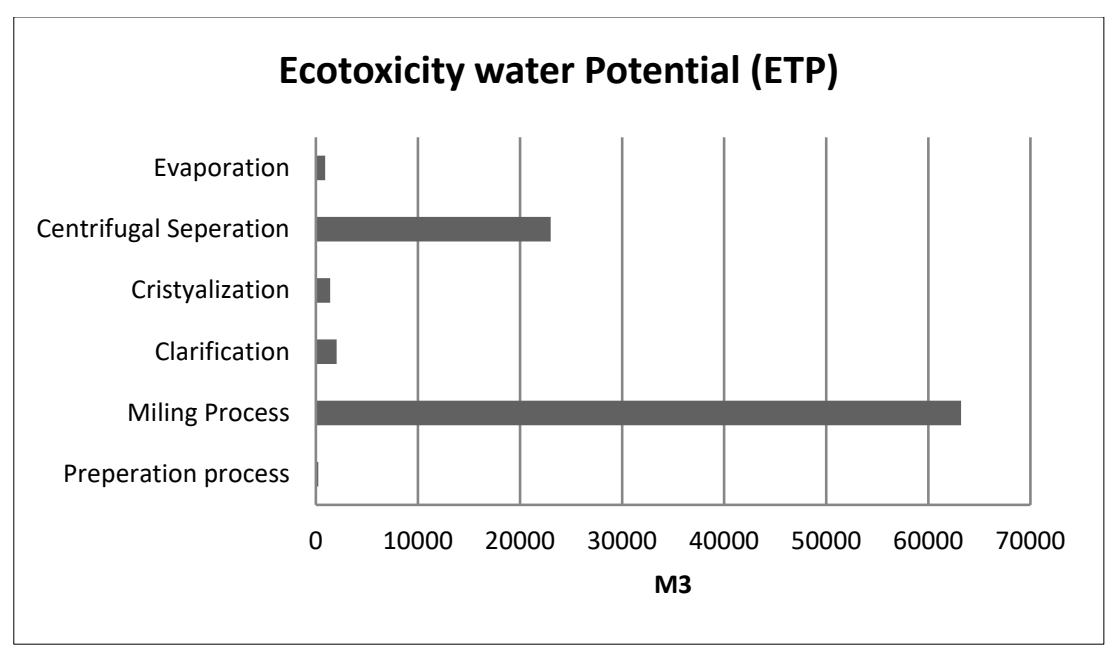

Gambar 6: Potensi Ecotoxicity Water pada produksi Gula Tebu

dengan software simapro bahwa selama proses produksi gula tebu menunjukkan hasil yang cukup significant pada kategori dampak Human Toxicity Air. Gambar 6 menunjukkan bahwa dalam produksi gula tebu sebanyak 225 ton menghasilakan kategori dampak Human Toxicity Air sebanyak 90788 m3. Sebagai tambahan, proses milling mempunyai kontribusi yang paling besar pada pencemaran kategori Human Toxicity Air dengan melepaskan ke udara sebanyak $63200 \mathrm{~m}^{3}(70 \%)$, diikuti oleh proses separation centrifugal sebesar $23000 \mathrm{~m}^{3}(25 \%)$, proses clarification memproduksi sebesar 2040 $\mathrm{m}^{3}(2 \%)$, selanjutnya proses crystallization menghasilkan sebesar $1400 \mathrm{~m}^{3}(2 \%)$, dan proses evaporation menghasilkan sebesar $913 \mathrm{~m}^{3}(1 \%)$, dan proses preperation sebesar $235 \mathrm{~m}^{3}(1 \%)$.

\section{KESIMPULAN DAN SARAN}

Hasil studi LCA menunjukkan bahwa ada potensi penurunan kulitas lingkungan selama proses pembuatan 255 ton gula tebu, dimana kontribusi terbesar terhadap dampak lingkungan adalah pada proses milling, diikuti oleh proses centrifugal separation, proses clarification, proses crystallization, proses evaporation, dan praproduksi secara berurutan. Dan besar prosentasi dampak lingkungan juga dijelaskan secara berurutan untuk semua proses, seperti pada pemanasan global sebesar $67 \%, 24 \%, 4 \%, 2 \%, 2 \%$ dan $1 \%$; deplesi ozon sebesar $70 \%$, $25 \%$, $2 \%, 2 \%, 1 \%$ dan $0 \%$; Eutrofication sebesar $69 \%$, $25 \%, 2 \%, 2 \%, 1 \%$, dan $1 \%$; Acidification sebesar $68 \%, 25 \%$, 2\%,2\%,2\%, dan $1 \%$; dan Human toxcicty air sebesar $70 \%, 25 \%, 2 \%, 2 \% 1 \% 1 \%$ dan
1\%. Oleh karena itu perlu melakukan strategi mitigasi untuk mengurangi potensi dampak lingkungan pada proses pembuatan gula tebu. Penulis menyarankan untuk menerapkan cleaner produksi/produksi bersih untuk mengurangi dampak lingkungan dari produksi tebu khususnya pada miling proses dan centrifugal proses.

\section{DAFTAR PUSTAKA}

Anne Renouf, M., Pagan, R. J., \& Wegener, M. K. (2011). Life cycle assessment of Australian sugarcane products with a focus on cane processing. International Journal of Life Cycle Assessment. https://doi.org/10.1007/s11367-0100233-y

Cardona, C. A., Quintero, J. A., \& Paz, I. C. (2010). Production of bioethanol from sugarcane bagasse: Status and perspectives. Bioresource Technology. https://doi.org/10.1016/j.biortech.2009. 10.097

Chauhan, M. K., Varun, Chaudhary, S., Kumar, S., \& Samar. (2011). Life cycle assessment of sugar industry: A review. In Renewable and Sustainable Energy Reviews. https://doi.org/10.1016/j.rser.2011.04.03 3

Curran, M. A. (2018). Life-cycle assessment. In Encyclopedia of Ecology. https://doi.org/10.1016/B978-0-12409548-9.09700-1 
Goldemberg, J., Coelho, S. T., \& Guardabassi, P. (2008). The sustainability of ethanol production from sugarcane. Energy Policy. https://doi.org/10.1016/j.enpol.2008.02. 028

Hauschild, M. Z., Rosenbaum, R. K., \& Olsen, S. I. (2017). Life Cycle Assessment: Theory and Practice. In Life Cycle Assessment: Theory and Practice. https://doi.org/10.1007/978-3-319-

56475-3

Hofsetz, K., \& Silva, M. A. (2012). Brazilian sugarcane bagasse: Energy and nonenergy consumption. Biomass and Bioenergy.

https://doi.org/10.1016/j.biombioe.2012 .06 .038

ISO. (2006). 14040: Environmental managementlife cycle assessment-Principles and framework. International Organization for Standardization.

Kementerian Perindustrian Republik Indonesia. (2018). Sektor-Sektor Manufaktur Andalan Tahun 2018. Kementerian Perindustrian Republik Indonesia.

Luo, L., van der Voet, E., \& Huppes, G. (2009). Life cycle assessment and life cycle costing of bioethanol from sugarcane in Brazil. In Renewable and Sustainable Energy Reviews. https://doi.org/10.1016/j.rser.2008.09.02 4

Murugan, A. M., \& Ranjit Singh, A. J. A. (2012). Sugarcane. In Valorization of Food Processing By-Products. https://doi.org/10.1201/b12816
Ramjeawon, T. (2008). Life cycle assessment of electricity generation from bagasse in Mauritius. Journal of Cleaner Production. https://doi.org/10.1016/j.jclepro.2007.11 .001

Renó, M. L. G., Lora, E. E. S., Palacio, J. C. E., Venturini, O. J., Buchgeister, J., \& Almazan, O. (2011). A LCA (life cycle assessment) of the methanol production from sugarcane bagasse. Energy. https://doi.org/10.1016/j.energy.2010.1 2.010

Renouf, M. A., Wegener, M. K., \& Pagan, R. J. (2010). Life cycle assessment of Australian sugarcane production with a focus on sugarcane growing. International Journal of Life Cycle Assessment. https://doi.org/10.1007/s11367-0100226-x

Silalertruksa, T., Pongpat, P., \& Gheewala, S. H. (2017). Life cycle assessment for enhancing environmental sustainability of sugarcane biorefinery in Thailand. Journal of Cleaner Production. https://doi.org/10.1016/j.jclepro.2016.06 .010

Sirait, M. (2018). Cleaner production options for reducing industrial waste: The case of batik industry in Malang, East JavaIndonesia. IOP Conference Series: Earth and Environmental Science, 106(1). https://doi.org/10.1088/17551315/106/1/012069 